\title{
Intermittent punishment of responding maintained by variable ratio reinforcement ${ }^{1,2}$
}

\author{
ARNOLD KAUFMAN \\ UNIVERSITY OF WISCONSIN, MILWAUKEE
}

Variable ratio reinforced behavior was observed in five female college students in daily sessions in which no punishment, continuous punishment, and intermittent (VI) punishment were programmed. In three of the five $S s$, punishment shock intensities strong enough to suppress all responding under continuous punishment had no effect when VI punishment was programmed at mean intervals ranging from 15.0 sec. to $.8 \mathrm{sec}$. Only one $S$ showed partial suppression, while all others showed either no suppression or complete suppression under VI punishment. The all or none suppression was related to the fact that partial suppression has virtually no effect in reducing shock frequency on the VI punishment schedule, although such suppression may result in substantial loss of reinforcement on the VR schedule.

The results of previous work on intermittent punishment of concurrently reinforced behavior have shown that when moderate to severe punishment is employed, stable response rates are established under intermittent punishment which fall somewhere between unpunished rates and the suppressed rates established by continuous punishment (Azrin, Holz, \& Hake, 1963; Zimmerman \& Baydan, 1963). However, all of the previous work on intermittent punishment has employed either continuous or variable interval (VI) reinforcement schedules. The present investigation was undertaken to examine the effects of intermittent punishment on human behavior maintained by variable ratio (VR) reinforcement, where any tendency toward suppression would be expected to lead to a drastic reduction in reinforcement.

Method

Five female college students were hired to serve for approximately $1550 \mathrm{~min}$. sessions. Ss were isolated in a small room containing a table and chair. On the table were mounted a push button (Grason-Stadler E8670A), and a panel which contained two stimulus lamps and an impulse counter. Within sessions, stimuli were programmed on a four-component multiple schedule. Throughout all of the $252 \mathrm{~min}$. components, push button responding was reinforced on a VR 75 schedule, the reinforcing stimulus consisting of a counter tally which represented one cent. Components 1 and 3 of the multiple schedule consisted of VR 75/No Punishment, with neither lamp illuminated; component 2 consisted of concurrent VR 75/Continuous Punishment, with the left corner lamp illuminated; and component 4 consisted of concurrent VR 75/VI Punishment, with the right corner lamp illuminated.

Punishment intensity was established on the first two punishment days by gradually increasing shock intensity in the continuous punishment component until responding was eliminated in that component but not substantially affected during the intermittent punishment component, which was always programmed in the initial sessions at $15 \mathrm{sec}$. VI. Pilot work had revealed that no suppressive effect occurred at $15 \mathrm{sec}$. VI punishment. The shock stimulus was a $60 \mathrm{cps}, 40 \mathrm{msec}$. pulse delivered on the index finger of the right hand. Ss were instructed to respond with the right hand.

After shock intensity had been established for each $\mathrm{S}$, two sessions were programmed at each of a number of increasing shock frequencies, i.e., the mean interval of the VI punishment decreased in component 4 . Ss, therefore, started with two days at $15 \mathrm{sec}$. VI in the intermittent shock component, and then received two days at successively higher frequencies until either complete suppression occurred in the VI punishment component, or continuous punishment was scheduled during both punishment components.

Results

The major results are summarized in Fig. 1. Points plotted are relative response rates in the continuous and intermittent punishment components. Relative rates are median responses per sec. during the 6 VI (filled circles) or 6 continuous (open circles) punishment components divided by the median responses per sec. during the 13 no-punishment components of the same session. Absolute response rates during the no-punishment components averaged about 4.5 responses per sec. Data are from the second of two days at each interval of the VI punishment schedule.
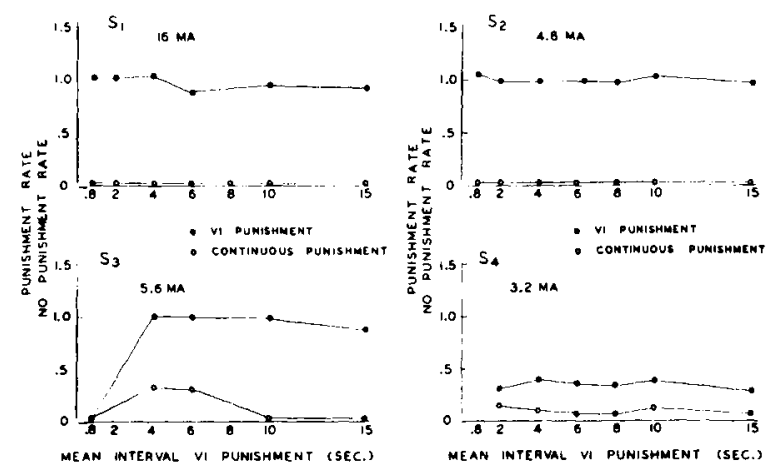

Fig. 1. Ratios of punished to unpunished responding during intermittent and continuous punishment. Ratios are plotted as a function of the VI punishment schedule programmed in component 4 of Mult (VR 75; Con VR75/Continuous Punishment; VR 75; Con VR75/VI Punishment) 
The major finding is that with the exception of $S_{4}$, responding of all Ss under VI punishment occurred either at the unpunished rate or not at all. Ss 1 and 2 showed no effect of VI punishment at any mean interval, including $.8 \mathrm{sec}$. Therefore, continuous punishment was programmed during both punishment components for those two Ss, as a result of whichall responding dropped out of component 4 . At no time did responding in the no-punishment components decrease from levels reached in previous sessions. In fact, absolute rates of responding during the no-punishment components tended to increase over successive sessions for all Ss. $\mathrm{S}_{3}$ showed no effect of VI punishment until the $.8 \mathrm{sec}$. interval was programmed, after which suppression was complete in the VI punishment component. $\mathrm{S}_{4}$ varied from other Ss in two ways. First, the shock intensity of $3.2 \mathrm{ma}$ finally used did not completely suppress $\mathrm{S}_{4}$ 's responding during the continuous punishment component, while, second, at that intensity intermittent shock punishment reduced the rate to about $1 / 3$ of the unpunished rate.

Data from $\mathrm{S}_{5}$ are presented in Fig. 2. The points plotted are again derived from rates during continuous and intermittent punishment divided by the unpunished rate in the same session. They are plotted over sessions, however, since $S_{5}$ was exposed only to VI $15 \mathrm{sec}$. punishment during component 4. In attempting to establish a shock intensity to be used during later sessions, $\mathrm{S}_{5}$ was moved up to $12.0 \mathrm{ma}$ on the second punishment day, at which point responding was completely suppressed during continuous punishment but was unaffected during $15 \mathrm{sec}$. VI punishment. In the next three sessions, however, $\mathrm{S}_{5}$ failed to respond during both punishment components, in spite of the fact that

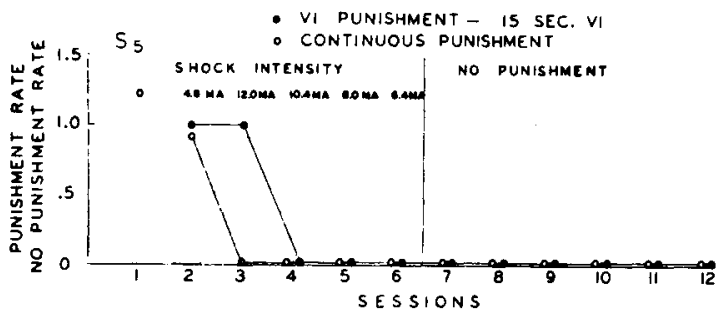

Fig. 2. Ratios of punished to unpunished responding (sessions 2 - 6) for $S_{5}$. Also, ratios of responding in former punishment periods with punishment no longer programmed (sessions 7 - 12). shock intensity was reduced over those three days from 12.0 to $6.4 \mathrm{ma}$. After day 6, the shock generator was turned off, but $S_{5}$ failed to respond in the former punishment components over the next six sessions of punishment extinction. VR 75 reinforcement was programmed in all components of sessions 7-12. Like Ss 1, 2 and 3, $\mathrm{S}_{5}$ also showed the all or none pattern of responding under intermittent punishment.

\section{Discussion}

It would appear that VI punishment is far less effective than continuous punishment in suppressing responding reinforced on a VR schedule. The tendency for responding on the VR schedule to occur at a very high rate or not at all is very similar to results obtained by Azrin (1959) in a study of punishment effects on behavior maintained by fixed ratio (FR) reinforcement. Azrin found that continuous punishment produced longer post-reinforcement pauses but did not affect running rate once the animal started to respond. A plausible hypothesis for the lack of partial suppression in most Ss under VR reinforcement is that unlike the case of interval schedules of reinforcement, where substantial suppression results in relatively little loss of reinforcement, the proportion of reinforcement loss under the VR schedule is directly a function of amount of suppression. In addition, under VI punishment of VR-maintained responding a substantial reduction in rate, although it results in significant reinforcement loss, does not greatly reduce the number of shocks received. Therefore, differential reinforcement for high rates is likely to be the overriding factor in determining rate when responding maintained by VR reinforcement is punished with mild or moderate shock intensities on a VI schedule.

\section{References}

Azrin, N. Punishment and recovery during fixed-ratio performance. J. exp. Anal. Behav., 1959, 2, 301-305.

Azrin, N., Holz, W., \& Hake, D. Fixed-ratio punishment. J. exp. Anal. Behav., 1963, 6, 141-148.

Ferster, C., \& Skinner, B. Schedules of Reinforcement. New York: Appleton-Century-Crofts, 1957.

Zimmerman, J., \& Baydan, N. Punishment of SA responding of humans in conditional matching to sample by time-out. J.exp. Anal. Behav., 1963, 6, 589-597.

\section{Notes}

1. This research was supported by grants MH 08430 from NIMH and RF 62:616 from the University of Wisconsin.

2. The help of Samuel Katchigan and John Uhlarik, who collected the data for this study, is gratefully acknowledged. 